\title{
«La Quimera»
}

\author{
Sagrario AZnAR AlmaZÁN
}

La publicación de "La Quimera" de Emilia Pardo Bazán, se inicia, por entregas, en las páginas de La Lectura durante el año 1903, pero su elaboración y redacción, al parecer más lentas de lo habitual en la autora, no finalizaron hasta 1905, año en que además aparece editado como libro. Como ya demostró Daniel Whitaker ${ }^{1}$, entre la versión por entregas y la versión en libro, la autora incluyó múltiples correcciones que si bien no afectaron sustancialmente a la temática, si supusieron una reveladora reelaboración y corrección de estilo más acorde con los cánones de la nueva estética decadentista «fin de siglo». En este sentido, bastante más neoromántico, parece evidente que la intencionalidad de la Pardo Bazán era simbolizar el mito clásico de la Quimera en el curso de una fuerte pasión, el ideal artístico del pintor Silvio Lago, haciendo gala de una profesión de fé idealista, categórica y rotunda que se verá confirmada en pasajes de la novela como el del diálogo de la Esfinge y la Quimera, en el primer capítulo, tomado al pie de la letra de "Las tentaciones de San Antonio" de Flaubert. La Esfinge simbolizaría la materia, el peso de la razón y la sensatez, mientras que la Quimera es lo intangible, el ideal, las ansias nunca satisfechas. El hombre, por su situación mortal, se debate entre ambas fuerzas, el apego a la realidad concreta y material y la necesidad de satisfacer sus ansias de absoluto que, desde luego, pueden canalizarse por el camino del arte, pero también, al menos desde la óptica de la última producción pardobazaniana, de la religión.

En cualquier caso, es curioso, lo que vamos a leer es la historia de un arribismo artístico. A estas alturas del siglo, la bohemia ha cambiado

WhitakeR, Daniel. «La Quimera» de Pardo Bazán y la literatura española finisecular», Madrid, Pliegos, 1988. 
mucho: ya no se nutre únicamente de aspirantes geniales sino también de fracasados que no han tenido más remedio que volver a ella y que han contribuido no poco a desprestigiarla. Por ésta y por muchas otras razones, el artista ahora pretenderá hacerse rico por su trabajo, como el burgués, y querrá que en una sociedad comercial se le reconozca un valor comercial. La pintura tenderá a convertirse en una profesión, de manera que o se triunfa adaptándose a los gustos de la clientela burguesa y se convierte uno mismo en burgués, o se fracasa y se caerá en una bohemia de la que Emilia Pardo Bazán demuestra, en la novela, no tener muy buena opinión. Como ya ha señalado Francisco Calvo Serraller ${ }^{2}$, «junto al Romanticismo surgen, apartir de 1830, dos tendencias rivales, la escuela del "bon sens" (a la que sin duda se adscribiría la Pardo Bazán) y la poesía de combate, el primer testimonio de la literatura y el arte políticamente comprometido con los partidos políticos. A la melancólica desilusión romántica, ese arte de interiores, le sucede una concepción utilitaria, social, extrovertida, con superficie comercial y política, un arte de exteriores. Es el momento de la adaptación, de la adaptación del arte a la sociedad burguesa y de la sociedad burguesa al arte. A partir de entonces, el momento de los artistas profesionales y empresarios, el momento de los burgueses sensibles, el bohemio pierde el aura romántica del rebelde para convertirse en un inadaptado, en un fracasado, en un ser pintoresco y tragicómico".

En este sentido, y a pesar de lo que se ha insistido en las similitudes ${ }^{3}$, son más importantes las diferencias entre La Obra de Zola y La Quimera, al menos en lo que a los protagonistas se refiere. Las semejanzas son, desde luego, obvias en muchos aspectos de la novela: la psicología de los artistas, el ambiente decadente y a la vez cosmopolita de la ciudad de París, donde se desarrolla una buena parte de la trama de los dos relatos, o el sustrato autobiográfico tan importante en ambos, pues resulta evidente que el novelista Pierre Sandoz es inequívocamente en La Obra "alter ego» de Zola, de la misma manera que lo es la compositora musical, Minia Dumbría, de Emilia Pardo en La Quimera. Pero las diferencias son más interesantes, y no sóio en lo que se refiere al ideal estético que ambos pintores persiguen (no hay coincidencia en el estilo pictórico de-

Calvo Serraller, Francisco. La novela del artista, Madrid, Mondadori, 1990, pág. 67.

3 Ver SOTElo VÁzQUEZ, MARISA. Introducción a La Quimera de EMILIA PARDO BAZÁn, Barcelona, Promociones y Publicaciones Universitarias, 1992; y Sotelo Vázquez, MARISA. "La obra de Emile Zola como modelo llterario de "La Quimera» de Emilia Pardo Bazán», Actas del x Congreso de la Asociación Internacional Hispanistas, agosto de 1989. 
fendido), sino, sobre todo, en la manera en que cada uno de ellos intenta llegar a su ideal. Es cierto que tanto en un caso como en otro es importante la influencia de las teorías de Lombroso ${ }^{4}$ y Nordau ${ }^{5}$ en el trazado psicológico de los protagonistas, pues los dos son víctimas de una misma lucha obsesiva y enervante por la perfección artística. Para ambos, sólo el arte, o, más específicamente, la pintura, dará sentido a sus vidas. Por ello, con obsesiva insistencia, declara Claude Lantiere: «Me moriría si dejara de pintar; prefiero pintar y morirme..."; y Silvio Lago: "iTriunfar o morir! mi Quimera es ésa y excepto mi Quimera... ¿qué me importa el mundo?»6. También a los dos esta búsqueda les lleva a desligarse de todos aquellos afectos o sentimientos que puedan obstaculizar su camino. En el caso de Silvio Lago nunca llega a haber vínculos humanos verdaderamente profundos y, por ejemplo, las sucesivas aventuras amorosas no son más que eslabones progresivamente abandonados en aras de su ideal artístico. El caso de Claude Lantiere, sin embargo, es mucho más trágico pues Zola lleva hasta el límite de lo descriptible el abandono y la miseria en que viven los dos seres que dependen de él: su mujer, que acaba enloqueciendo de celos por la pintura, y su hijo, un niño deforme que muere prematuramente.

Se trata, desde luego, de dos personajes egoistas, neuróticos, desquiciados y despóticos que no parecen sentir ningún afecto más allá de la pasión por el arte, pero la diferencia está en que Claude Lantiere no hace concesiones, es un absoluto "héroe moderno" y como tal muere en el suicidio, mientras que Silvio Lago, ya lo veremos, se enriquece como retratista de la alta burguesía o de la aristocracia y descuida la parte más "elevada» de su arte. Es la distancia que separa al rebelde idealista y al cazador de oportunidades que transforma el talento en una empresa rentable.

Porque La Quimera no es, de ninguna manera, la historia de un genio, sino la de un artista prostituido. Y con esto entraríamos en uno de los

4 Teoría según la cual la marca del genio se refleja incluso en la peculiaridad de los rasgos físicos del individuo.

5 MAX NORDAu en su libro Degeneración (1893) expone una teoría según la cual el genio era una patología que podia manifestarse de muy diversas maneras desde el criminal al artista, al que se consideraba un «degenerado superior». La PARDO BAZÁN utilizará la misma expresión en 1911 al referirse al protagonista de La Obra de Zola: "La Obra" es la novela de un pintor genial, de un "degenerado superior» que no acierta a producir la obra maestra soñada". En PARDO BAZÁN, EMILIA, EL Naturalismo. La Literatura Francesa Moderna. Obras Completas, Tomo XLI, Madrid, Renacimiento, s/a, pág. 111.

5 Pardo Bazán, E. La Quimera, Op. cit., 1992, pág. 154. 
temas más apasionantes de la segunda mitad del siglo XIX: la prostitución del artista o, lo que podría ser lo mismo, la identificación del artista con la prostituta. Pero no es lo mismo. Aquí no tenemos más remedio que ver dos vertientes diferentes para aclarar las cosas: por un lado está el artista que hace concesiones sobre su «pureza» y vende al burgués lo que éste quiere comprar, un tipo de artista que jamás se autoidentifica con la prostituta, aunque los más "puros» puedan verle como tal; $y$, por otro, aparece el artista que, marginales por marginales, se ve, en el mundo burgués, en el mismo lado de la balanza que la prostituta y es consciente de ello. En el primero de los casos, como ha señalado Vaughan ${ }^{7}$, «el artista que clamó por ser la conciencia de su tiempo no estaba haciendo nada más que ofrecerle entretenimiento. En el tiempo de las ambigüedades artísticas, ésta fué la más notoria». Pero es bastante más interesante el segundo tipo: el artista marginal, voluntaria o involuntariamente, que se identifica con la prostituta como tipo humano que, por muchas razones, le es afín. Leamos, por ejemplo, a Baudelaire:

"Gavarni (el caricaturista) ha creado la Lorette. Existía, desde luego, mucho antes, pero él la ha completado; creo incluso que él es quien ha inventado la palabra. La Lorette, ya se ha dicho, no es la «querida», esa cosa del Imperio, condenada a vivir en unión fúnebre con el cadáver metálico al cual se unía, general o banquero. La Lorette es una persona libre, va y viene. Tiene casa abierta. No tiene dueño; frecuenta los artistas y los periodistas. Hace lo que puede por tener espíritu» 8

La identificacion está clara. La Lorette no es ya el artista a sueldo que tiene que soportar todo para ganarse la vida. Su prostitución está a otro nivel y le permite ser libre, tener espíritu. $Y$ cuando Baudelaire habla de la Lorette no podemos por menos que pensar en la Olimpia de Manet o en la Nana que también pintó basándose en la novela de Zola. Quizás por eso Balzac cree que los artistas tienen algo rameril y Emilia Pardo Bazán en La Quimera, cuando Silvio está en Parfs, uno de sus momentos de esfuerzo más sincero, le permite admirar el trabajo en una prostituta («Hasta la daifa que recorre un trozo de acera, siempre el mismo, y que interpela al transeúnte, muestra la aplicación de la laboriosidad, tiene dejos de obrera, compelida por la tarea forzosa" " ${ }^{9}$, para añadir a renglón seguido, quizás por asociación de ideas: "La conseja bohemia artística, del descuido y la hoganza entrecortada por hipos de genio y arrechuchos de inspiración,

\footnotetext{
Vaughan, WiLliam, Romantic Art, Londres, Thames and Hudson, 1988, pág.26.

Baudelaire, Charles. Curiosidades estéticas, Madrid, Ediciones Júcar, 1988, pág. 197.

Pardo BazÁn, Emilia. La Quimera, Op. cit., 1992, pág. 420.
} 
con risas, trampas y fumaduras de pipas, se derrumbaba en su romántica falsedad", haciendo una defensa del trabajo como base del genio que dura varias páginas.

$Y$ es que, en el siglo $x I x$, curiosamente, al mismo tiempo que se crea en la novela la leyenda del artista, se va forjando otra para las prostitutas y cortesanas que, aunque desde luego estaba muy alejada de la cruda realidad, tenía una razón de ser. Sólo Zola les dedica tres libros: La confesión de Claude (1865), Madelaine Ferat (1868) y la mencionada Nana, pero también los hermanos Goncourt escribieron La modelo y Dumas hijo La Dama de las Camelias. Es decir, al márgen de que las prostitutas aparezcan frecuentemente en las novelas de artista como un espíritu afín con el cual éste puede entenderse, ellas poco a poco van conquistando su propio lugar y su leyenda.

Pero Silvio Lago pertenece mucho más al primer tipo que hemos mencionado y está muy lejos de hacerse partícipe de las palabras de un Courbet ${ }^{10}$ al que, al menos en principio, él admira en una parte de la novela. En este sentido es interesante hacer un estudio de los dos artistas a los que Emilia Pardo Bazán le contrapone a lo largo de la narración: el «impresionista" Solano y el pintor de la aristocracia francesa, Marbley.

En lo que se refiere a Solano aparece por primera vez en el círculo de pintores con los que el protagonista trabaja en la Sociedad y Silvio Lago lo describe identificándose más con él que con cualquier otro: "Hay uno, sin embargo, rabioso, emberrechinado como yo: se profesa impresionista y se llama Solano. Tiene unos ojos que giran, que miran azorados, insensatamente: ojos de raposo cogido en la trampa" ${ }^{11}$. Por eso, cuando ya ha conseguido un primer éxito como retratista de la alta sociedad y se le ha mencionado elogiosamente en La Época, entre todas las reacciones de sus amigos pintores él mira cuidadosamente la de éste último: «A la siguiente noche, en la Sociedad, mientras Cenizate me suelta un fogoso abrazo de felicitación, percibo en los demás, y especialmente en los que creía algo amigos míos, una ironía y una sorpresa malévola, gestos impertinentes. En un grupo se dan el codo y ríen; en otro bajan la nariz y se chapuzan en el dibujo. Solano, el impresionista, me da la espalda" ${ }^{12}$. Y no

10 "Confio siempre ganarme la vida con mi arte sin tener que desviarme nunca de mis principios ni el grueso de un cabello, sin traicionar mi conciencia ni un solo instante, sin pintar ni siquiera lo que pueda abarcarse con una mano sólo para darle gusto a alguien o por vender con más facilidad». Carta de 1854 citada en GoMBricH, Historia del Arte, Madrid, Alianza Forma, 1990.

1 Pardo Bazán, EmIlia. La Quimera, Op. cit., 1992, pág. 162.

12 Pardo Bazán, Emilia. La Quimera, Op. cit., 1992. pág. 172. 
se engaña al respecto: «Además de la envidia percibo otra cosa todavía más mortificante, jel desprecio!" ${ }^{13}$.

Envidia que, además, se volverá contra Silvio Lago en la siguiente aparición de el «impresionista», cuando Lago es ya un pintor de éxito completo, francamente incómodo consigo mismo, y se lo encuentra por la calle acompañado de un «maestro» a quien él admira sinceramente: «Al volver la cabeza ví que a aquella hora temprana, bajo un sol ya picón, caminaban a pie dos hombres... Les reconocí. El uno era Solano, el impresionista, derrotado, despeinado, retorcido, alrededor del cuello una corbata grasienta -es fácil que la camisa esté peor que la corbata-y sus ademanes alocados, su trepidar de ojos, daban animación febril al manoteo con que se dirigia a su acompañante. Este... Al verle percibí el acostumbrado golpe, el que sufrimos al encontrarnos ante personas en quienes pensamos ahincadamente, $y$ que, distantes al parecer de nuestro horizonte $y$ nuestro destino, influyen en él, sin embargo, de un modo decisivo y secreto. Era nada menos que aquel... que yo quisiera ser; el que -sosegadamente, firmemente, desenvolviendo hilos de tradición tenuísimos, algo que procede de los grandes maestros españoles de la pincelada franca y el contraste de luz vigoroso-, se ha abierto ancho camino, sin artificios, sin concesiones, gran artista secundariamente pero, en primer termino, reproductor literal y pujante de una verdad de la naturaleza, de una violencia del color y de la luz, de un aspecto fiero y esplendente de la tierra española. Con el corazón palpitante me saciaba de mirarle, cual si de la contemplación apasionada del seide y del fanático pudiese salir algo de asimilación» ${ }^{14}$.

Son dos pintores que sólo trabajan para sí mismos, uno ha triunfado y al otro la Pardo Bazán le impone, quizás por bohemio, un final aciago después de la Exposición. El Salón, durante todo el siglo xIx era, sin duda, el eje central en torno al cual giraba la vida artística y la vida de los artistas porque, como centro de todas las polémicas, era prácticamente la única posibilidad que tenían los pintores de ser conocidos. «Lograr exponer en el Salón no estuvo jamás al alcance de todos, sobre todo si el aspirante contravenía, por sus aspiraciones innovadoras, el gusto establecido, pero, además, pronto se pudo comprobar que la ampliación indiscriminada del mismo, haciéndose más tolerantes los jurados de admisión, tampoco solucionaba el problema pues, a mayor apertura, mayor confusión. Por otra

3 Pardo Bazán, Emilia. La Quimera, Op. cit, 1992, pág. 173

Pardo Bazán, Emil.1a. La Quimera, Op. cit., 1992, pág. 275. 
parte, el gusto del público, dominado en su mayor parte por la clase media burguesa, era aún más conservador que el de los jurados oficiales, con to que, sin una adecuada información, una crítica periodística mayoritariamente volcada a ridiculizar las novedades y unos cuadros amontonados en las peores condiciones, no es extraño que sus reacciones fueran las del escándalo y la risa, dentro del más absoluto rechazo» ${ }^{15}$. Rechazo que lleva a Solano a tirarse del viaducto ante los ojos de Silvio Lago: «Nadie entre la multitud le conoce; es su destino que no le conozcan, pues le faltaron puños para violentar a la Fama; pero como tiene la cara hacia arriba, y sus ojos, antes giratorios y dementes, ahora vidriados, inmóviles, se han posado tantas veces en mi con insultante ironía (sin recordar que éramos hermanos), yo le reconozco, y me quedo pegado a la barandilla, fascinado por la fascinación poderosa, que responde al sentido de terror y misterio que rodea nuestra vida: la fascinación de la muerte... ${ }^{16}$. Pero fascinado también por el fracaso romántico que el suicidio supone, un acto de rebeldía completa, lo que Walter Benjamín llamaría «el gesto moral de la conciencia moderna».

En el extremo opuesto, Silvio Lago conoce en París a Marbley, pintor de la alta sociedad francesa, absolutamente prostituido, arribista pleno, que sólo le provoca rechazo y repugnancia: «No era fácil casar la persona y la pintura de Marbley. Silvio conocía su "Harem turco», obra de juventud, brote de savia pronto agotada, y, juzgándole por su mejor página, profesábale cierto respeto. Quedó estupefacto ante lo que mostraba el belga: el ampuloso retrato de una dama chilena, uno o dos estudios de paisaje -composiciones amaneradas, plagiarias, de colorido falso y pobre-. Por mucho que Silvio se despreciase y rebajase, en su ardiente humildad de catecúmeno, no le era posible comparar con aquella desdicha sus pasteles. En éstos, siquiera, convenía reconocer gentileza, fluidez, elegancia de postura, leve idealidad, mariposeante por cima de 10 ficticio y afeminado del procedimiento; pero en la producción del belga no había sino la nulidad irremediable, la esterilidad del páramo, la angustia del manantial seco. Veiase que el talento de Marbley había sido flor de juventud (...) Quedaba en fracasado resuelto el pelear, no por la gloria, sino por el provecho. Lo peor era eso: Marbley, convencido, amargamente desengañado, no cejaba: iba a su fin sin escrúpulos. Para no carecer de su clientela rutinaria y antojadiza (...) apoyábase en la mujer, 
tejía complicadas redes galantes que sólo a fuerza de estrategia no le enredaban también (...)" "1?.

Debatiéndose entre ambos extremos, despreciando a Marbley pero incapaz de mantener el espíritu de sacrificio (o de riesgo) que caracterizaba a Solano, la trayectoria de Silvio Lago, salpicada por innumerables quejas que se alargan a través de toda la novela demostrando la absoluta consciencia del pintor ${ }^{18}$, parece determinada de antemano. Silvio Lago llega a Madrid lleno de buenas intenciones y se instala en un «atelier» más o menos mísero, en un completo interior romántico. «La portera sube a barrer de mala gana, a traerme agua y a arreglarme la cama en un diván (...) ha visto que mis muebles se reducen a dos caballetes, una caja de lápices $y$ veinte libros (...). Estoy, pues, en plena bohemias ${ }^{19}$. Es su lugar de trabajo, un lugar interior, como ya ha señalado Francisco Calvo Serraller ${ }^{20}$, en un doble sentido: un espacio físico, pero, también, un espacio mental, ese rincón del alma donde el artista sueña y concibe. En el interior se produce la concepción, el alumbramiento, el acto artísticamente esencial. El artista todavía se refugia, se adentra, se aparta de la circulación (aún no es el "fláneur») y en el interior de su taller se almacenan todos sus sueños.

Por eso es tan importante como cambia. Cuando empieza a triunfar compra algunas cosas para adornarlo, para aburguesarlo. "Después de mil regateos (...) me decido por dos fraileros, cuatro sillas de laca y seda brochada, un canapé Imperio, una alfombra pequeña y viejisima, pero de colorido grato, un contador italiano aparatoso (falso quizás), dos o tres Talaveras recompuestos y un arcón tallado, basto, que me servirá de carbonera» ${ }^{21}$. Cuando ya ocupa un lugar seguro dentro de la alta sociedad, acaba por mudarse a un taller mejor situado cerca del Palacio de Bibliotecas y Museos, y se convierte en un dandi, pero no en un dandi de Baudelaire, sino en un dandi stendhaliano. Como muy bien ha apuntado René Girard ${ }^{22}$, "Baudelaire ve en el «dandi» un resto de las "épocas

17 Pardo BazÁn, Emilia. La Quimera, Op. cit., 1992, pág. 435-436.

18 «De modo que ya se revela mi porvenir. Subir escaleras como los maestros de piano, esperar en la antesala a que me mande pasar la señora, retratar con luces de interior y a la hora que me ordenen... Y lo más vil es temblar no a esas humillaciones, sino a que no llegue el caso de sufrirlas..." (La Quimera, pág. 169).

"Me revolvia en la cama furioso, al observar como mis actos se acompasan servilmente a la marcha de la realidad, mientras mi espíritu sigue abrazado a la Quimera" (La Quimera, pág. 178).

19 Pardo Bazán, Emilia. La Quimera, Op. cit., pág. 158.

20 Calvo Serraller, Francisco. La novela del artista, Op. cit. 1990. pág. 52.

21 Pardo BAZÁ, Emilia. La Quimera, Op . cit., 1992, pág. 179.

22 GiRARD, René. Mentira romántica y verdad novelesca, Universidad de Caracas, 1963, pág. 119. 
aristocráticas", Stendhal, por el contrario, ve en él el producto de los tiempos modernos (...) (El dandi) se define por la afectación de frialdad indiferente. Pero esta frialdad no es la del estoico, es una frialdad calculada para inflamar el deseo, una frialdad que no cesa de repetir a los demás "Yo me basto a mí mismo". El dandi quiere hacer copiar a los demás el deseo que pretende sentir por sí mismo". Manera mediante la cual Silvio Lago consigue que la alta sociedad le desee y desee su obra.

Por eso es tan importante el último cambio de taller en un París en el que el pintor vuelve a recuperar todos sus buenos propósitos, vuelve, en cierto modo, a la bohemia. "El taller mal barrido por la descuidada portera (...) tenia un aspecto decaído, ese velo polvoriento que influye sobre las imaginaciones vivas sugiriendo aprensiones de fracaso (...). Los muebles rotos y mal encoiados del artista que viajaba, desbaratándose como si a propósito lo hiciesen. Los tapices era jirones. Todo gritaba la penuria del dueño de aquel refugio» ${ }^{23}$.

Porque, es cierto, en la vida de Silvio Lago también hay un intento de trayectoria artística «seria» paralelo a su trabajo como retratista. Empieza como un pintor de la naturaleza, dentro de lo que podríamos llamar un «realismo regionalista» muy teñido de romanticismo y con toda el aura moral que implicaba la postura de los realistas y que tan acertadamente ha explicado Linda Nochlin ${ }^{24}$. Es el momento en que admira a Courbet, un pintor que, con el tiempo, acabará por rechazar absolutamente contagiado por las ideas estéticas de la propia Pardo Bazán. Después del suicidio de Solano y de haber conocido a Espina Doncel, una mujer sofisticada y decadente, muy fin de siglo, empieza su conversión artística acercándose a Baudelaire y a sus ideas sobre «lo articial». Es la propia Espina Doncel quien le dice: «Hoy se hacen cosas más encantadoras que nunca (...). Lo natural es un mote con que se tapa lo grosero. ¿De dónde saca usted que lo natural, por ser natural, ya es bello? Al contrario, tonto, al contrario. Lo bello es... lo artificial»" ${ }^{25}$. Palabras en las que campea la clara influencia del Elogio al maquillaje que Baudelaire publicó en 1863. La condena baudeleriana del mal natural es inequivoca y frente a la grosería y al instinto del crimen que la naturaleza infunde en el hombre, se alza la "alta espiritualidad de la toilette", esa majestad superlativa de lo artificial que Baudelaire no tiene reparos en identificar con las formas de adorno más primarias: la moda, los cosméticos, el ornato o las galas.

Pardo Bazán, Emilia. La Quimera, op. cit., 1992, pág. 461.

Nochlin, LINDA. El Realismo, Madrid, Alianza Forma, 1991, págs. 29 y ss.

Pardo Bazán, Emilia. La Quimera, Op. cit., 1992, pág. 351. 
Aunque la conversión completa no llegará, naturalmente, hasta París, y, sobre todo, después de un viaje por Bélgica y Holanda (un "viaje interior» en el estilo más romántico subrayado por la forma epistolar en que se redacta esta parte de La Quimera) en el que conoce a un periodista, Limsöe que, delante de los cuadros de los primitivos flamencos y principalmente de el Cordero místico de Van Eyck, le convierte al prerrafaelismo, un credo estético que la Pardo Bazán no sólo conocía sino que apoyaba basándose, en parte, en sus ideas religiosas.

En cualquier caso, esta lucha interior de Silvio Lago es una lucha fustrada porque el pintor no consigue hacer más que un cuadro "sincero", La recolección de la patata en la Mariña, en su primera época realista ${ }^{26}$. De lo demás, nada, y al final, cuando ya Silvio Lago, enfermó de tuberculosis ${ }^{27}$, vuelve a Galicia a morir, la Pardo Bazán pone en su boca las siguientes palabras: "No moriré de este mal; pero suponga usted, por un momento, que muriese... Es aterrador, Minia... ¿Qué quedaba de mi? Cosas que ya no responden a mi sentir, ideas que ya rechazo... Y lo verdaderamente íntimo, lo que he ido descubriendo... jeso nadie lo sabría! ieso se iría conmigo al otro mundo!» ${ }^{28}$. El artista no ha conseguido enderezar su vida, ser fiel al Ideal, y muere solo, rodeado únicamente de las fotos y las cartas de las mujeres a las que ha retratado, un espejismo de su vida galante. Quizás, simplemente, Emilia Pardo Bazán quería mostrar la historia de un pintor, como tantos otros, un arribista incapaz de llegar a rozar a la Quimera. Pero quizás sería más lógico pensar que la autora, solidaria con los artistas, está planteando el precio, no sólo de hambre y miseria, que tenían que pagar los pintores por su vocación en una sociedad en la que, ella entre otros, intentaban hacerse un sitio, un sitio que Emilia Pardo Bazán no se cansa de subrayar como necesario, como imprescindible para la civilización.

26 El cuadro lo describe EMILIA PARDo BAZÁn en la novela en las páginas 189-190.

27 EMtLIA PARDO BAZÁn se llegó a plantear la posibilidad de un suicidio para SILVIO LAGo e incluso esta orientación la hacía explicita en algunas páginas del capítulo segundo que acabó suprimiendo. (Ver Apéndice Textual de la edición que hemos venido manejando). Pero, al final, sus ideas religiosas se lo impidieron.

28 Pardo BazAn, EMILIA. La Quimera, Op. cit., 1992, pág. 544. 